\title{
Caracterização estrutural e papel do fator de crescimento derivado de plaquetas (PDGF) na foliculogênese ovariana
}

\author{
Structural Characterization and Role of Platelet-Derived Growth Factor (PDGF) in Ovarian \\ Folliculogenesis
}

\begin{abstract}
Ivina Rocha Brito', Isadora Machado Teixeira Lima', Márcia Viviane Alves Saraiva', José Roberto Viana Silva $^{2}$, Ana Paula Ribeiro Rodrigues' ${ }^{1}$ \& José Ricardo de Figueiredo'
\end{abstract}

\begin{abstract}
Background: The platelet-derived growth factor (PDGF) is expressed in a wide variety of cell types, exerts a potent mitogenic role and acts on the growth, differentiation and cell chemotaxis. Studies have shown that during folliculogenesis, PDGF and their receptors are expressed in oocytes, granulosa cells and thecal cells of ovarian follicles at different developmental stages in several species. Although exist many information about its expression sites, as well as about its action in different cells types, the role of PDGF on ovarian folliculogenesis remains understudied. Thus, this article aims to review issues related to PDGF, suggesting the involvement of this mitogenic factor during follicular development.

Review: Along this work, it was shown aspects related to structural characterization of PDGF and its receptors, as well as PDGF expression in different cells types, emphasizing its importance to follicular development. PDGF family is composed by four polypeptide chains (each encoded by a different gene), which are synthesized in the form of inactive pro-proteins. After a proteolytic processing, these chains undergo homo or heterodimerization, resulting in five isoforms (PDGF-AA, - BB, - AB, -CC e -DD). The cellular effects of these different PDGF isoforms are mediated by binding, with different specificities, to three transmembrane receptors isoforms of type tyrosine kinase generated by the association of subunits $\alpha$ e $\beta$ (PDGFR- $\alpha \alpha,-\alpha \beta$, $\beta \beta)$. PDGF was initially purified from platelets, being later verified its production by many varieties of cell types. It acts as an important mitogenic factor, especially to cells of mesenchymal origin as fibroblasts and smooth muscle cells, and also exerts a role on cellular migration and survival. Studies with PDGF and its receptors have demonstrated its importance as a paracrine growth factor for normal embryo development and angiogenesis. Although the action of this growth factor has been shown in several cellular responses, its role in ovarian folliculogenesis of mammals is understudied. Folliculogenesis, event initiated at pre-natal life in most species, can be defined as the process of follicular formation, growth and maturation, beggining with the primordial follicle formation and resulting in preovulatory stage. Until the present moment, the different PDGF types and their receptors were detected in ovarian follicles of murines, rodents, swines and humans according to developmental stage. Evidences suggest that this growth factor may acts as a potent regulator of ovarian function, increasing DNA synthesis in granulosa cells and stimulating theca cells growth in swines. In addition, PDGF has shown benefic effects in in vitro maturation of bovine oocytes when associated with follicle stimulating hormone (FSH).

Conclusion: Nevertheless, the specific actions of PDGF on ovarian follicles development have not been described due to lack of data available in the literature about this subject. Therefore, this review was performed to clarify the involvement of this growth factor in the regulation of ovarian function in mammals. However, it is necessary to perform additional studies that may provide a greater understanding about the importance of PDGF during folicullogenesis.
\end{abstract}

Keywords: PDGF, folliculogenesis, mammalian, platelet, fator de crescimento, atructural characterization.

Descritores: PDGF, foliculogênese, mamíferos, plaquetas, growth factor, caracterização estrutural. 


\title{
I. INTRODUÇÃO
}

\section{FATOR DE CRESCIMENTO DERIVADO DE PLAQUETAS (PDGF)}

\subsection{Caracterização estrutural}

\subsection{Estrutura dos genes que codificam os PDGFs}

\subsection{Processamento proteolítico dos PDGFs}

\subsection{Expressão dos PDGFs em diferentes tipos celulares}

\section{RECEPTORES DE PDGF}

\subsection{Ativação do receptor}

\subsection{Padrões de sinalização induzidos pela ligação PDGF-PDGFR}

\author{
3.2.1. Padrão RAS-MAPK \\ 3.2.2. Padrão PI3K \\ 3.2.3. Padrão PLC- $\gamma$ \\ 3.2.4. Padrão Src
}

\section{PAPEL DOS PDGFS NA FOLICULOGÊNESE}

\subsection{Foliculogênese}

4.2. Importância do PDGF para o desenvolvimento folicular

\section{CONSIDERAÇÕES FINAIS}

\section{INTRODUÇÃO}

O fator de crescimento derivado de plaquetas (PDGF) é uma glicoproteína dimérica que foi primeiramente identificada por Ross et al. [95], além de Kohler e Lipton [56] como um agente mitogênico para células mesenquimais presentes no soro sanguíneo de macacos e camundongos, respectivamente. Diferentes estudos relataram a produção de PDGF por megacariócitos, monócitos/macrófagos, células endoteliais, células musculares lisas vasculares, fibroblastos, neurônios e células embrionárias, dentre outros tipos celulares $[4,27,96,121]$.

No ovário mamífero, a expressão do PDGF foi identificada em oócitos, células da granulosa e células da teca de folículos em diferentes estádios de desenvolvimento. Além disso, evidências indicam a sua atuação nos vários estádios da foliculogênese, bem como no desenvolvimento embrionário inicial. A foliculogênese consiste na formação e no crescimento folicular, culminando com a liberação de um oócito maturo capaz de ser fertilizado [117].

O desenvolvimento folicular é coordenado por uma complexa comunicação bidirecional entre oócito, células da granulosa e células da teca, que promove a interação de fatores de crescimento locais e gonadotrofinas entre os compartimentos foliculares. Os fatores intraovarianos, incluindo o PDGF, participam ativamente do controle do crescimento folicular promovendo a multiplicação das células da granulosa e da teca, o crescimento oocitário e regulando a ação das gonadotrofinas de origem hipofisária $[22,120]$.

Estudos recentes têm contribuído para identificar os locais de síntese do PDGF nos folículos ovarianos e evidenciado seus efeitos específicos na foliculogênese. Desta forma, a presente revisão aborda a caracterização estrutural do PDGF e de seus receptores, bem como sua atuação em diversos tipos de células, destacando a sua participação na foliculogênese.

\section{FATOR DE CRESCIMENTO DERIVADO DE PLAQUETAS (PDGF)}

\subsection{Caracterização estrutural}

A família PDGF é composta por 4 cadeias polipeptídicas (A, B, C e D), cada uma codificada por um gene diferente [115]. Cada molécula de PDGF é formada por duas cadeias polipeptídicas antiparalelas ligadas por pontes dissulfídicas através de homo ou heterodimerização, originando 5 isoformas: PDGF-AA, PDGF-AB, PDGF-BB, PDGF-CC e PDGF-DD. Devido a um splincing alternativo nos transcritos de PDGF-A, este é sintetizado na forma de duas diferentes cadeias, sendo uma com 196 e outra com 211 resíduos de aminoácidos, que diferem somente na sua extremidade C-terminal. Ambas as isoformas são encontradas naturalmente em diferentes tipos de células, sendo a de 
menor tamanho mais abundante [67,127]. Já as cadeias de PDGF-B, -C e -D apresentam 241, 345 e 370 resíduos de aminoácidos, respectivamente [89].

Os PDGFs pertencem à uma família estrutural e funcionalmente relacionada aos fatores de crescimento vasculares, incluindo os fatores de crescimento do endotélio vascular (VEGFs) [23]. Os fatores PDGF e VEGF contêm um domínio principal, chamado de domínio de homologia PDGF/VEGF (Figura 1). Este domínio é constituído por aproximadamente 100 resíduos de aminoácidos e é, evolutivamente, uma estrutura altamente conservada presente em diferentes organismos, incluindo a Drosophila [70] e várias espécies de cobras $[49,123]$. É caracterizado pela presença de 8 resíduos de cisteínas conservadas, constituindo o nó de cisteína, onde dois resíduos ( 2 e 4 ) estão envolvidos nas ligações dissulfídicas intermoleculares, e o restante participa das ligações intramoleculares. Esta estrutura está presente em todos os membros da família PDGF e está envolvido tanto na dimerização das duas cadeias como na ligação e ativação do receptor. Além disso, todos os PDGFs possuem um peptídeo sinal e uma extensão $\mathrm{N}$ - ou C-terminal envolvidas na regulação das propriedades biológicas destes fatores. Os PDGF-A e -B apresentam uma pequena extensão N-terminal e uma extensão C-terminal, também chamada de motivo estrutural de retenção, contendo uma alta proporção de aminoácidos básicos envolvidos na ligação destes fatores a componentes da matriz extracelular [59, 82]. Robbins et al. [93]

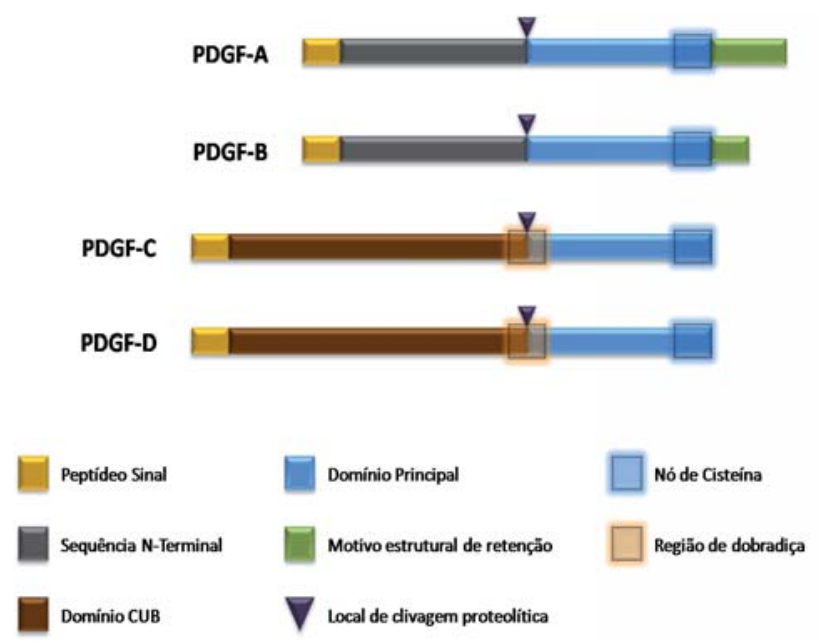

Figura 1. Caracterização estrutural das cadeias de PDGF. As cadeias A e B são caracterizadas pela presença de um "motivo estrutural de retenção", enquanto as cadeias C e D apresentam o domínio CUB. observaram que grande parte do PDGF-BB expresso permanece associado à membrana plasmática. Os PDGF-C e -D não contêm a extensão C-terminal, mas apresentam o domínio CUB como parte da sua extensão N-terminal, o qual liga-se ao domínio principal através de uma cadeia com cerca de 80-100 aminoácidos, chamada de região de dobradiça $[3,64]$. O domínio CUB é comumente encontrado em diferentes tipos de proteínas, incluindo proteases extracelulares e proteínas de superfície celular, dentre outras [7], e participa da interação proteína-proteína ou proteína-carboidrato, além de regular a distribuição extracelular das cadeias $-\mathrm{C}$ e $-\mathrm{D}$ inativas.

\subsection{Estrutura dos genes que codificam os PDGFs}

Os genes que codificam as 4 cadeias de PDGFs estão localizados em 4 cromossomos diferentes. Em humanos, os genes PDGFA e PDGFB estão localizados nos cromossomos 7 e 22 [5,16,112], enquanto os genes $P D G F C$ e $P D G F D$ estão nos cromossomos 4 e 11, respectivamente [115]. Todos os genes apresentam uma organização muito semelhante no que se refere ao número e tamanho dos éxons. No entanto, uma grande diferença é observada entre o tamanho dos íntrons. Os genes $P D G F A$ e $P D G F B$ apresentam íntrons de aproximadamente $20 \mathrm{~kb}$, enquanto os genes $P D G F C$ e $P D G F D$ apresentam íntrons de aproximadamente $200 \mathrm{~kb}$ [63].

Os genes $P D G F A$ e $P D G F B$ possuem 7 éxons (Figura 2), em que o éxon 1 codifica o peptídeo sinal e os éxons 2 e 3 codificam a sequência $\mathrm{N}$-terminal. Os éxons 4 e 5 são responsáveis pela codificação do domínio principal e o 6 da extensão C-terminal. A cadeia A é expressa em duas diferentes isoformas, devido ao splicing alternativo, com ou sem a sequência codificada pelo éxon 6. Em ambos os genes o éxon 7 não é codificado $[6,46,94]$.

$\mathrm{O}$ gene $P D G F C$ consiste em 6 éxons, enquanto o gene $P D G F D$ apresenta um éxon adicional. Em ambos os genes, o éxon 1 codifica o peptídeo sinal e os éxons 2 e 3, o domínio CUB. No gene PDGFC, o éxon 4 codifica a região de dobradiça e no gene $P D G F D$ esta região é codificada pelos éxons 4 e 5. Consequentemente, o domínio principal é codificado pelos éxons 5 e 6 no gene $P D G F C$, e 6 e 7 no gene $P D G F D$ [63].

\subsection{Processamento proteolítico dos PDGFs}

Todos os PDGFs são sintetizados nos retículos endoplasmáticos das células produtoras na forma de moléculas precursoras inativas, denominadas pró-proteínas. 
Essas moléculas são então dimerizadas e necessitam de diferentes processamentos proteolíticos para a sua ativação [93]. No entanto, atualmente não existem evidências de regulação da secreção dos PDGFs, sendo estes liberados de forma contínua [25].

Os PDGF-A e -B são ativados por um padrão exocítico. Após a dimerização das suas cadeias nos retículos endoplasmáticos, os dímeros são transportados para o complexo de Golgi, onde ocorre o processamento proteolítico, caracterizado pela remoção da extensão N-terminal das moléculas. PDGFAA é processado em uma molécula de $30 \mathrm{kDa}$, a qual é carregada por vesículas até a superfície da célula para liberação extracelular por exocitose. Já o PDGF-BB, é processado em dois diferentes produtos finais: uma molécula de $24 \mathrm{kDa}$, mais abundante, a qual é degradada por lisossomos, e outra de 30 $\mathrm{kDa}$, liberada da mesma forma que o PDGF-AA [83]. A protease envolvida na conversão da pró-PDGF-A para PDGF-A ainda é desconhecida, no entanto, evidências sugerem que a furina, uma endoprotease dibásica, seja a responsável por essa conversão [101]. Da mesma forma, a enzima correspondente para a conversão da pró-PDGF-B para PDGF-B ainda não foi identificada, mas acredita-se que também seja uma pró-proteína convertase.

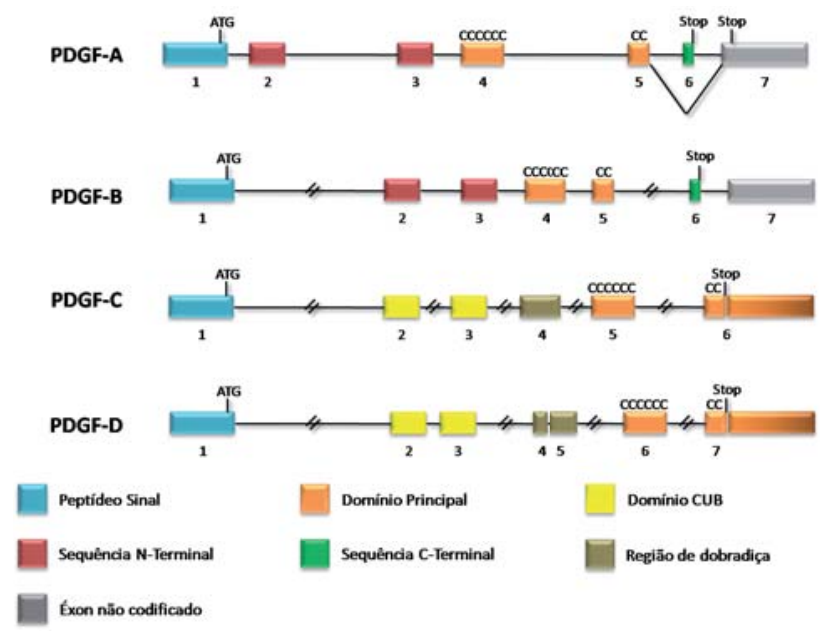

Figura 2. Estrutura dos genes que codificam as quatro cadeias de PDGF. Duas isoformas de PDGF-A podem ser originadas devido a um splicing alternativo, onde são utilizados dois códons de terminação localizados em éxons diferentes. Os códons de iniciação (ATG) e terminação (Stop) são representados na figura. Os íntrons e éxons não são apresentados em escala, sendo os íntrons com comprimento superior a $5 \mathrm{~kb}$ representados por (//). Figura adaptada de X. Li e U. Eriksson [63].
As isoformas -C e -D são secretadas sem a remoção da extensão $\mathrm{N}$-terminal, ou seja, na sua forma inativa, sugerindo que ambos os fatores são ativados por proteólise extracelular [23,92]. A ativação requer a remoção do domínio CUB, incluso na extensão Nterminal, e liberação do domínio principal para que possa haver a ligação da proteína ao receptor. As enzimas plasmina e ativador de plasminogênio de tecido (tPA) têm sido demonstradas como as responsáveis pela clivagem proteolítica do PDGF-C, enquanto somente a plasmina pode remover o domínio CUB do PDGF-D [23]. Além disso, PDGF-C e -D parcialmente processados, ou seja, com remoção de somente um domínio CUB do homodímero (chamados de hemidímeros), ainda são capazes de se ligar ao receptor. No entanto, esta ligação ocorre com baixa afinidade e desencadeia uma resposta antagônica, ou seja, a ligação do hemidímero impede que ocorra a dimerização do receptor e, consequentemente, a transdução do sinal [89].

\subsection{Expressão dos PDGFs em diferentes tipos celulares}

O padrão de expressão de cada PDGF vem sendo amplamente estudado, demonstrando que este fator é sintetizado por uma grande variedade de tipos celulares. O PDGF-AA tem sido identificado como produto de células epiteliais, osteosarcomas, melanomas e glioblastomas [36,79], sendo necessário durante a embriogênese e organogênese, bem como no desenvolvimento do sistema nervoso central e da crista neural $[9,26,29,51,52,62,108,109]$. Já o PDGF$\mathrm{BB}$, é expresso em células do endotélio vascular, megacariócitos e neurônios, sendo implicado principalmente na angiogênese [1].

O PDGF-CC é expresso em células epiteliais, musculares e progenitoras neurais, e em adultos parece contribuir para a cicatrização de ferimentos, proliferação de fibroblastos, migração epitelial, vascularização e infiltração de neutrófilos. Além disso, a presença de PDGFCC foi demonstrada em tecidos ativamente angiogênicos, como placentas, alguns tecidos embrionários e tumores, sugerindo um papel para esta isoforma durante a angiogênese [61]. Já a expressão de PDGFDD é bem menos caracterizada, embora tenha sido observada em fibroblastos e células musculares lisas [1].

Quanto à ocorrência de PDGF-AB, acredita-se que esta seja específica para seres humanos [111]. Plaquetas humanas e algumas linhagens de células cultivadas expressam naturalmente as cadeias -A e -B, podendo originar as três isoformas, sugerindo que a 
formação de dímeros é um processo aleatório [31,32,34]. Esta observação é baseada em trabalhos que utilizam células transfectadas com os genes das cadeias - $\mathrm{A}$ e - $\mathrm{B}$, onde verificou-se a formação tanto de heterodímeros quanto de homodímeros [42]. No entanto, Hammacher et al. [31] demonstraram que as plaquetas são a maior fonte do heterodímero $-\mathrm{AB}$, enquanto os homodímeros -AA e -BB são encontrados em menor proporção. In vivo, a proliferação de fibroblastos dérmicos humanos é estimulada pelo PDGF-AB [48], sendo detectado ainda um efeito terapêutico na cicatrização de ferimentos para esta isoforma [72].

\section{RECEPTORES DE PDGF}

Os eventos celulares mediados pelos PDGFs acontecem após a ligação da molécula e a consequente ativação do receptor, o qual é uma glicoproteína transmembranária do tipo tirosina quinase. Estes receptores são formados por duas cadeias polipeptídicas, $\alpha$ e $\beta$, constituídas por 1.089 e 1.106 resíduos de aminoácidos, respectivamente $[12,13]$. Após a ligação do PDGF, duas cadeias de receptor dimerizam-se e, dependendo da configuração do ligante e do padrão de expressão do receptor, diferentes isoformas podem ser formadas: PDGFR- $\alpha \alpha$, PDGFR- $\beta \beta$ e PDGFR- $\alpha \beta$ [39]. As isoformas diméricas PDGF-AA, PDGF-AB, PDGF-BB e PDGF$C C$ se ligam ao PDGFR- $\alpha \alpha$, enquanto PDGF-BB e PDGF-DD interagem com o PDGFR- $\beta \beta$. O heteroxdímero PDGFR- $\alpha \beta$, por sua vez, pode ser formado após a ligação das isoformas PDGF-AB, PDGF-BB e PDGF-CC $[10,130]$.

Estruturalmente, os PDGFRs são caracterizados por uma região extracelular, composta por cinco domínios semelhantes à imunoglobulinas, sendo os três primeiros domínios responsáveis pela interação com os ligantes [129], enquanto o domínio 4 contribui para a dimerização das subunidades de receptores [81]. Apresentam ainda uma região transmem-branária e outra intracelular, formada por um domínio justamembranário seguido pelo domínio tirosina quinase e, por fim, uma cadeia C-terminal (Figura 3).

As cinco isoformas diméricas de PDGF possuem habilidades distintas para se ligar e ativar os receptores, conforme mostrado em um estudo realizado em ratos, utilizando células osteoblásticas fetais, o qual sugere que os diferentes tipos de receptores não só se ligam seletivamente a uma ou mais isoformas de PDGF, como também são capazes de responder de forma diferente a estas [86]. Desta forma, a expressão de ambos os receptores e de cada um dos cinco PDGFs é controlada de forma independente, dando ao sistema PDGF/PDGFR uma grande flexibilidade. A proporção de isoformas de PDGF e PDGFRs expressas varia grandemente entre os diferentes tipos de células. Algumas células apresentam apenas uma das isoformas de PDGFR, como as células precursoras da glia [35], plaquetas humanas [119] e células endoteliais de fígado de ratos [40], que expressam a isoforma $\alpha \alpha$, ou células musculares lisas e endoteliais de capilares de camundongos [107], que expressam somente a isoforma $\beta \beta$. Outros tipos de células expressam ambas as isoformas, simultânea ou separadamente, como, fibroblastos e células musculares lisas [107].

As isoformas homodímeras exercem um potente efeito mitogênico, promovendo o crescimento de células tumorais $[38,90]$, a reorganização dos filamentos de actina [20] e o aumento intracelular de $\mathrm{Ca}^{2+}$ [17]. A ativação do receptor $\beta \beta$ estimula a quimiotaxia, enquanto o receptor $\alpha \alpha$ pode inibir ou estimular a migração de diferentes tipos de células, incluindo fibroblastos, células musculares lisas e epiteliais $[57,100,125,128]$. O receptor $\beta \beta$ inibe a comunicação entre as células através de junções do tipo gap [43] e exerce ainda um efeito antiapoptótico [124].

Contudo, os níveis de expressão dos receptores para PDGF não permanecem constantes nas células,

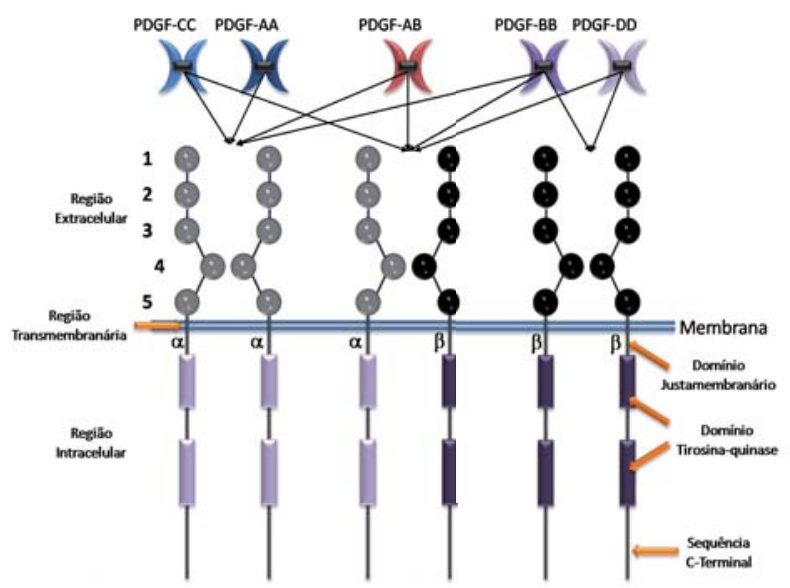

Figura 3. Interações PDGF-PDGFR e organização estrutural dos receptores para os PDGFs. Diferentes isoformas de PDGF ligam-se e dimerizam as subunidades $\alpha$ e $\beta$ dos receptores. Cada receptor é constituído de uma região extracelular, a qual apresenta 5 domínios sememlhantes à imunoglobulinas, uma região transmembranária e outra intracelular, composta pelos domínios justamembranário e tirosina-quinase. 
podendo causar diferentes estímulos externos, tais como inflamação, desenvolvimento embrionário ou diferenciação, exercer em influência sobre a expressão desses receptores celulares permitindo a ligação de alguns PDGFs, mas não de outros [97].

\subsection{Ativação do receptor}

Após a ligação do PDGF ao seu receptor, ocorre a dimerização das subunidades de receptores, caracterizada pela aproximação dos domínios citoplasmáticos de cada subunidade, permitindo a fosforilação da tirosina entre as diferentes subunidades do dímero (transfosforilação). Essa dimerização é essencial para a ativação da quinase e consequente ativação do receptor [53], o qual sofre mudanças conformacionais que permitem que a enzima, em atividade basal, fosforile um resíduo específico de tirosina. Este evento leva ao desbloqueio da quinase, a qual aumenta sua atividade enzimática agindo sobre outros resíduos de tirosina, bem como sobre outros substratos.

Nove e doze locais de fosforilação têm sido identificados nos receptores $\alpha$ e $\beta$, respectivamente [37]. As tirosinas fosforiladas dentro do domínio quinase (Tyr-849 no receptor $\beta$ e Tyr-857 no receptor $\beta$ ) regulam a atividade catalítica das quinases, enquanto as tirosinas fosforiladas fora deste domínio criam locais específicos para a ligação das moléculas responsáveis pela transdução do sinal [39].

Em geral, as moléculas sinalizadoras podem ligar-se aos receptores através de diferentes domínios, como, os domínios SH2 (domínio de homologia à Src 2) e PTB (domínio de ligação da fosfotirosina), que reconhecem tirosinas fosforiladas, o domínio SH3, o qual reconhece regiões ricas em prolina, o domínio PH (domínio de homologia $\alpha$ proteína pleckstrin), que reconhece membrana fosfo-lipídica, e o domínio PDZ, o qual reconhece sequên-cias C-terminal específicas [37].

No entanto, todas as enzimas envolvidas na transdução da mensagem gerada pela formação do complexo PDGF-PDGFR utilizam o domínio SH2 para interagir com o receptor [13].

\subsection{Padrões de sinalização induzidos pela ligação PDGF-PDGFR}

Após a ativação do receptor, diferentes mecanismos de sinalização são recrutados. Estes envolvem as moléculas Ras-MAPK, fosfatidilinositol 3-quinase (PI3K), Fosfolipase C $\gamma 1$ (PLC- $\gamma$ ) e Src. Outras moléculas, como Grb2, Grb7, Nck, Shc, e Crk não possuem atividade enzimática e desempenham a função de proteínas adaptadoras, intermediando a interação do receptor com a molécula sinalizadora [11]. Além disso, membros da família Stat (Stat-1, -3, -5a, - $\beta$ e -6) também se ligam aos PDGFR e atuam como fatores transcricionais que, após a fosforilação da tirosina, são direcionados para o núcleo das células onde afetam a transcrição de genes específicos [116].

A maioria das células responsivas ao PDGF são dependentes do contato com moléculas presentes na matriz extracelular. Esse contato é mediado pelas integrinas, as quais são receptores transmembranários localizados na superfície das células. A interação entre os PDGFRs, as integrinas e moléculas específicas da matriz extracelular levam à formação de adesões focais, onde vários padrões de sinalização são iniciados [14], aumentando a migração e a proliferação celular, e prevenindo a apoptose [2,24]. A seguir, são descritas as mais importantes vias de sinalização ativadas pelos receptores de PDGF.

\subsubsection{Padrão Ras-MAPK}

$\mathrm{O}$ receptor de fator de crescimento ligado à proteína 2 (Gbr2) é uma pequena proteína citoplasmática de $25 \mathrm{kDa}$, constituída por dois domínios, SH3 e SH2 [66, 104]. O Gbr2 está constitutivamente ligado a uma região rica em prolina da proteína SOS (Son of Sevenless), uma permutadora GDP/GTP para RAS, formando o complexo Gbr2/SOS. Uma vez ativado, este complexo é então recrutado para a membrana da célula onde se liga ao receptor através do domínio SH2 da Grb2 e, desta forma, permite a ativação de RAS. A proteína RAS liga-se à quinase Raf-1, a qual inicia eventos em cascata da via da proteína quinase ativada por mitógenos (MAPK) [11]. Após a ativação da MAPK, esta fosforila uma grande variedade de substratos membranares e citoplasmáticos, bem como fatores de transcrição e, assim, pode contribuir para a regulação de diferentes processos celulares, tais como crescimento, migração e diferenciação [39].

\subsubsection{Padrão PI3K}

$\mathrm{O}$ fosfatidilinositol 3-quinase (PI3K) desempenha um importante papel na transdução do sinal intracelular, podendo ser ativado pela maioria dos receptores do tipo tirosina quinase. O PI3K consiste em um complexo heterodimérico composto por uma subunidade reguladora, p85, e uma subunidade catalítica, p110. Similarmente a outras proteínas contendo o domínio SH2, o PI3K forma complexos com tirosinas fosforiladas de receptores ativos. Sua principal 
função é converter fosfatidilinositol 4, 5-bifosfato (PIP2) em fosfatidilinositol 3, 4, 5-trifosfato (PIP3), o qual atua como segundo mensageiro, ativando um grande número de moléculas efetoras. As respostas celulares mediadas pela ativação da via PI3K incluem reorganização das fibras de actina, quimiotaxia, crescimento celular e inibição da apoptose [118].

O PI3K, juntamente com membros da família $\mathrm{Src}$ e as quinases fosforiladas presente nos receptores, podem estar envolvidos na regulação do processo de internalização dos receptores para PDGF $[47,76,110]$. A ligação da proteína ao receptor induz a internalização do complexo ligante/receptor em endossomos, podendo esse complexo ser dissociado e o receptor devolvido à membrana, ou ainda degradado, devido à fusão dos endossomos com lisossomos [110].

\subsubsection{Padrão PLC- $\gamma$}

Da mesma forma que o PI3K, a PLC- $\gamma$ é imediatamente recrutada pelo receptor tirosina quinase fosforilado, ligando-se através do seu domínios $\mathrm{SH} 2$. Após sua ativação, a PLC- $\gamma$ hidrolisa seu substrato, o PIP2, originando duas moléculas, PIP3 e diacilglicerol, que irão atuar como segundos mensageiros. O PIP3 estimula a liberação de $\mathrm{Ca}^{2+}$ intracelular, o qual se liga à calmodulina, ativando, posteriormente, uma família de proteínas quinases dependentes de calmodulina (CaMKs), enquanto o diacilglicerol, juntamente com o $\mathrm{Ca}^{2+}$, ativa membros da família de proteínas quinase $\mathrm{C}$ (PKC) [4]. A PLC- $\gamma$ estimula diversos processos celulares, tais como angiogênese, proliferação, crescimento e motilidade de diferentes linhagens de células [50].

\subsubsection{Padrão Src}

As proteínas da família Src são um tipo de tirosina quinase citoplasmática não receptora, ativadas a partir da fosforilação dos resíduos de tirosina presentes no domínio justamembranário do receptor [28,41,58]. A ativação das proteínas Src, Fyn e Yes, as quais são os membros desta família envolvidos na sinalização induzida pelos PDGFs, resulta no crescimento e/ou na diferenciação celular [58] e são essenciais para a transmissão do sinal mitótico [114].

\section{PAPEL DOS PDGFS NA FOLICULOGÊNESE}

\subsection{Foliculogênese}

A foliculogênese ovariana consiste no processo de formação e crescimento dos folículos, seguindo uma sequência de acontecimentos característicos que iniciam com o estabelecimento da população folicular no ovário durante a vida pré-natal, na maioria das espécies, e terminam com a ovulação [117]. O folículo é considerado a unidade morfológica e funcional do ovário mamífero, sendo responsável pela síntese e secreção de hormônios esteróides e fatores de crescimento e pela liberação de um oócito maturo através da ovulação. Essas funções atuam de forma interdependente e complementar, sendo necessárias para o sucesso da reprodução [88]. Um oócito circundado por células da granulosa e da teca constituem um folículo, o qual deve proporcionar as condições ideais para a manutenção da viabilidade, crescimento e liberação de um oócito maturo no processo de ovulação [15]. Os folículos podem ser classificados de acordo com o grau de desenvolvimento em pré-antrais (primordiais, primários e secundários) e antrais (terciários e pré-ovulatórios) [102].

Os folículos primordiais constituem grande parte do estoque de gametas femininos no ovário, sendo formados por um oócito imaturo envolto por uma única camada de células somáticas de formato pavimentoso [45]. Após sua formação, esses folículos podem imediatamente iniciar o seu crescimento ou permanecer quiescentes por dias, meses ou anos [117], até serem estimulados a iniciar seu desenvolvimento. Este evento é denominado ativação folicular e é marcado por mudanças qualitativas e quantitativas, incluindo modificações no metabolismo e na estrutura folicular [103].

A transição do folículo primordial para primário é caracterizada por alterações morfológicas como o aumento do diâmetro oocitário, a proliferação das células da granulosa e a transformação no formato destas células de pavimentoso para cúbico. Assim, quando o oócito é circundado por uma única e completa camada de células da granulosa de morfologia cúbica, os folículos são denominados primários [30].

À medida que os folículos iniciam o crescimento, as proteínas que irão formar a zona pelúcida começam a ser sintetizadas [60]. Enquanto isso, a multiplicação das células da granulosa dos folículos primários leva à formação de várias camadas destas células ao redor do oócito, formando os folículos secundários. Neste estádio, as células da granulosa apresentam uma extensiva rede de junções do tipo gap ou intercomunicantes, que correspondem a canais membranários que permitem a passagem de nutrientes, íons inorgânicos, segundos mensageiros e pequenos metabólitos entre as células [54]. Ainda 
nesta fase, a zona pelúcida é claramente identificada ao redor do oócito e os precursores das células da teca são recrutados do estroma ovariano [85].

Com o crescimento dos folículos secundários e a contínua proliferação das células da granulosa, ocorre a formação de uma cavidade repleta de líquido folicular denominada antro. A partir desse estádio os folículos passam a ser denominados terciários ou antrais e são caracterizados pelo aumento acentuado do diâmetro folicular ocasionado pelo crescimento do oócito, multiplicação das células da granulosa, da teca e acúmulo de fluido antral [18]. Tal fluido corresponde ao ambiente ao qual o oócito é submetido durante o seu desenvolvimento e maturação, sendo considerado de grande importância para a determinação da qualidade oocitária. Dentre os componentes do fluido folicular, destacam-se hormônios esteróides e pituitários, citocinas, fatores de crescimento, proteínas séricas e eletrólitos [122].

O último estádio do desenvolvimento folicular ocorre em todas as espécies, geralmente a partir da puberdade [18], quando a liberação de altos níveis de hormônio luteinizante (LH) estimula a formação do folículo pré-ovulatório. Tal estádio é caracterizado por um oócito secundário, cujo núcleo encontra-se na segunda divisão meiótica, circundado pelas células do cumulus, formando o complexo cumulus-oócito. As células da granulosa dos folículos pré-ovulatórios param de se multiplicar em resposta ao LH, o qual possibilita que os folículos atinjam os estádios finais de desenvolvimento e ovulem, originando corpos lúteos [77].

Apesar do amplo conhecimento existente sobre as alterações morfológicas e funcionais que ocorrem com os folículos ovarianos durante seu desenvolvimento, ainda é limitado o conhecimento acerca dos fatores que regulam cada uma dessas etapas. Uma gama de fatores de crescimento e hormônios vêm sendo estudados, conforme descrito por Fortune et al. [21], e as evidências apontam que a dinâmica folicular é regulada por uma complexa interação de substâncias, dentre as quais podem ser citados os hormônios esteróides, as gonadotrofinas e os fatores de crescimento. Dentre os fatores que atuam regulando o desenvolvimento folicular, pode-se destacar o PDGF, cuja importância na foliculogênese é abordada a seguir.

\subsection{Importância do PDGF para o desenvolvimento folicular}

Diversos estudos vêm sendo desenvolvidos com o intuito de demonstrar a importância do PDGF para o desenvolvimento folicular. Nilsson et al. [78] caracterizou o PDGF como um fator de crescimento parácrino produzido pelo oócito, que atua sobre as células da granulosa e da teca intersticial promovendo a transição de folículos primordiais para primários [78]. Os diferentes tipos de PDGF e seus receptores foram detectados em folículos ovarianos de acordo com o estádio de desenvolvimento em murinos [126] e ratas [105]. Nesta última espécie, após análise por imuno-histoquímica, as proteínas PDGFA, -B e -C, e o receptor PDGFR- $\alpha \alpha$ foram localizados em corpos lúteos, indicando um possível papel deste fator durante o processo de ovulação e luteogênese [106]. Em suínos, o PDGF-A e o PDGFR-ootêm sido observados em oócitos e células da granulosa de folículos em estádios iniciais de crescimento [80], enquanto em humanos a isoforma -A foi identificada em grandes folículos antrais [87]. Ainda em humanos, McWilliam et al. [71] verificaram a presença de PDGF-AB no fluido folicular e de seu receptor em extratos de células da granulosa luteínicas isolados do líquido antral.

No folículo ovariano, a localização e a ação dos receptores para PDGF têm sido identificadas no oócito, nas células da granulosa e células da teca em diferentes espécies $[19,99,113]$. Em suínos, o PDGFR- $\beta \beta$ tem sido localizado na camada de células da teca de indivíduos adultos [113]. Já em ovários de ratas, as proteínas PDGFR- $\alpha \alpha$ e PDGFR- $\beta \beta$ foram encontradas em oócitos de folículos primordiais e primários. Além disso, o PDGFR- $\beta \beta$ também foi demonstrado em células da teca de folículos primários, secundários e antrais e em células da pré-granulosa/ granulosa de folículos primordiais, secundários e antrais, enquanto o PDGFR- $\alpha \alpha$ foi demonstrado em células da teca do estroma e de folículos em todos os estádios de desenvolvimento [105].

Através da técnica de hibridização in situ, foi demonstrada a presença de RNAm para PDGF-B, PDGF-C e PDGF-D em células da teca de folículos secundários, e somente para PDGF-D em oócitos de folículos primordiais e primários de ratas [105]. Nilsson et al. [78] verificou que o PDGF estimula a expressão do RNAm para Kit Ligand (KL), embora não tenha verificado o efeito deste fator sobre a expressão de PDGF e de seus receptores. Isso sugere que o PDGF promove a ativação de folículos primordiais através de um mecanismo que envolve o aumento da expressão do RNAm para KL [84]. Em oócitos não fertilizados de camundongas, foi identificado o RNAm para PDGF-A, o qual desaparece durante o 
estádio embrionário de 2 células e reaparece no estádio de 4 células [91], sugerindo um possível papel do PDGF na maturação do oócito e desenvolvimento embrionário durante a pré-implantação. Em oócitos suínos, e ainda em células da teca de folículos antrais avançados, Okamura et al. [80] também demonstraram a expressão de RNAm para o receptor PDGFR- $\alpha \alpha$.

Estudos recentes têm identificado a atuação dos PDGFs em folículos pré-antrais de roedores [78,105,126], nos quais observou-se que a adição das isoformas -A e -B ao meio de cultivo promoveu o crescimento de folículos primordiais [78] e secundários [105]. Além disso, a atividade proliferativa de células da teca de folículos antrais de ratas [19] e porcas $[68,99,113]$ também foi estimulada por PDGFs.

Atuando em sinergia com o hormônio folículo estimulante (FSH), os PDGFs induziram a formação de receptores para $\mathrm{LH}$ em células da granulosa de ratas [74,75]. Knecht e Catt [55] mostraram que o PDGF aumenta a atividade do AMPc estimulada pelo FSH, a produção de progesterona e a formação de receptores para LH em células da granulosa de ratas. O LH, por sua vez, induz o aumento dos níveis de RNAm para os PDGF-BB e -DD, e para o receptor $\beta$ em ovários de ratas, sugerindo um importante papel para este fator durante a luteogênese [106]. Schmahl et al. [98] demonstraram ainda que mutações nos genes de todas as isoformas de PDGFs ocasionam uma deficiência na produção de esteróides pelas células, sugerindo que estes fatores também atuam na regulação da esteroidogênese em camundongas.

Por outro lado, Michel et al. [73] verificaram que, em suínos, o PDGF não afeta a secreção de progesterona pelas células da granulosa. Além disso, Taylor [113] demonstrou que os PDGF-AB e -BB inibem a secreção de androstenediona e progesterona estimulada pelo LH em células da teca suínas. Nesta espécie, em células tecais cultivadas, o PDGF aumentou a síntese de estradiol na presença do fator de crescimento semelhante à insulina-1 (IGF-1) [99]. Além disso, Duleba et al. [19] observaram um efeito aditivo de PDGF-AB e IGF-1 sobre a síntese de DNA nas células da teca intersticiais de ratas. De forma similar, May et al. [68] sugeriram um efeito sinérgico entre PDGF e IGF-1 na proliferação de células da teca de suínos. Além disso, nesse mesmo estudo, verificou-se que o fator de crescimento epidermal (EGF) atua potencializando a ação do PDGF em células da teca. Por outro lado, em células da granulosa, o PDGF tem demonstrado aumentar a atividade proliferativa do EGF e do fator de crescimento transformante $-\alpha$ (TGF- $\alpha$ ) [69].

Em bovinos, a adição de FSH ao meio de maturação in vitro (MIV) contendo PDGF-AB, aumentou a proporção de oócitos inseminados que atingiram os estádios de mórula e blastocisto [33]. Bortolotto et al. [8] examinaram os efeitos do PDGF, da insulina e do retinol, bem como de suas interações na MIV de oócitos bovinos, e verificaram que a insulina e o PDGF, associados ou não, aceleraram a maturação nuclear, sendo suas ações potencializadas pelo retinol. A observação de que blastocistos humanos também respondem ao cultivo com PDGF indica uma provável expressão de receptores para este fator durante o desenvolvimento inicial [65].

\section{CONSIDERAÇÕES FINAIS}

Conforme demonstrado, a família PDGF é composta por 5 membros (PDGF-AA, -BB, -AB -CC e -DD), os quais têm sido amplamente estudados nos últimos anos quanto à sua estrutura e atuação. Especialmente com relação à foliculogênese, estudos demonstraram que o PDGF, bem como seus receptores, estão expressos em oócitos, células da gra-nulosa e células da teca de folículos ovarianos em diferentes estádios de desenvolvimento e em diferentes espécies. Estes dados sugerem uma atuação para este fator desde o processo de ativação folicular até o crescimento posterior destes folículos e matu-ração dos oócitos, seguido pelo desenvolvimento embrionário inicial. Entretanto, pode-se verificar que as informações disponíveis não são suficientes para descrever o papel específico do PDGF sobre o desenvolvimento folicular. Portanto, estudos adicionais são necessários para proporcionar o completo entendimento acerca da importância deste fator de crescimento durante a foliculogênese. 
Brito I.R., Lima I.M.T., Saraiva M.V.A., Silva J.R.V., Rodrigues A.P.R.\& Figueiredo J.R. 2010. Caracterização estrutural e papel do fator de crescimento derivado de plaquetas (PDGF)... Acta Scientiae Veterinariae. 38(3): 221-236.

\section{REFERÊNCIAS}

1 Andrae J., Gallini R. \& Betsholtz C. 2008. Role of platelet-derived growth factors in physiology and medicine. Gene \& Development. 22(10): 1276-1312.

2 Assoian R.K. 1997. Anchorage-dependent cell cycle progression. The Journal of Cell Biology. 136(1):1-4.

3 Bergsten E., Uutela M., Li X., Pietras K., Östman A., Heldin C.H., Alitalo K. \& Eriksson U. 2001. PDGF-D is a specific, protease-activated ligand for the PDGF beta-receptor. Nature Cell Biology. 3(5): 512-516.

4 Berridge M.J. 1993. Inositol trisphosphate and calcium signalling. Nature. 361(6410): 315-325.

5 Betsholtz C., Johnsson A., Heldin C.H., Westermark B., Lind P., Urdea M.S., Eddy R., Shows T.B., Philpott K., Mellor A.L., Knott T.J. \& Scott J. 1986. cDNA Sequence And Chromosomal Localization of human platelet-derived growth factor Achain and its expression in tumour cell lines. Nature. 320(6064): 695-699.

6 Bonthron D., Collins T., Grzeschik K.H., Van Roy N. \& Speleman F. 1992. Platelet-derived growth factor A chain: confirmation of localization of PDGFA to chromosome 7p22 and description of an unusual minisatellite. Genomics. 13(2): $257-263$.

7 Bork P. \& Beckmann G. 1993. The CUB domain. A widespread module in developmentally regulated proteins. Journal of Molecular Biology. 231(2): 539-545.

8 Bortolotto E.B., Gonçalves P.B.D., Neves J.P., Costa L.F.S., Maciel M.N., Montagner M.M., Farias A.M. \& Stranieri P. 2001. Fator de crescimento derivado das plaquetas, retinol e insulina na regulação da maturação nuclear de oócitos bovinos e suas conseqüências no desenvolvimento embrionário. Arquivo Brasileiro de Medicina Veterinária e Zootecnia. 53(2): 191-197.

9 Boström H., Willetts K., Pekny M., Levéen P., Lindahl P., Hedstrand H., Pekna M., Hellström M., Gebre-Medhin S., Schalling M., Nilsson M., Kurland S., Törnell Heath J.K. \& Betsholtz C. 1996. PDGF-A signaling is a critical event in lung alveolar myofibroblast development and alveogenesis. Cell. 85(6): 863-873.

10 Cao R., Bråkenhielm E. \& Li X. 2002. Angiogenesis stimulated by PDGF-CC, a novel member in the PDGF family, involves activation of PDGFR-alphaalpha and -alphabeta receptors. FASEB Journal. 16(12): 1575-1583.

11 Cattaneo E. \& Pellicci P.G. 1998. Emerging roles for SH2/PTB-containing Shc adaptor proteins in the developing mammalian brain. TINS. 21(11): 476-481.

12 Claesson-Welsh L. 1994. Platelet-derived growth factor receptor signals. Journal of Biological Chemistry. 269(51): 32023-32026.

13 Claesson-Welsh L. 1996. Mechanism of action of platelet-derived growth factor. International Journal of Biochemistry \& Cell Biology. 28(4): 373-385.

14 Clark E.A. \& Brugge J.S. 1995. Integrins and signal transduction pathways: the road taken. Science. 268(5208): $233-239$.

15 Cortvrindt R. \& Smitz J.E.J. 2001. In vitro follicle growth: Achievements in mammalian species. Reproduction Domestic Animal. 36(7): 3-9.

16 Dalla-Favera R., Gallo R.C., Giallongo A. \& Croce C.M. 1982. Chromosomal localization of the human homolog (c-sis) of the simian sarcoma virus onc gene. Science. 218(4573): 686-688.

17 Diliberto P.A., Gordon G.W., Yu C.L., Earp H.S. \& Herman B. 1992. Platelet-derived growth factor (PDGF) a receptor activation modulates the calcium mobilizing activity of the PDGF b receptor in Balb/c3T3 fibroblasts. Journal of Biological Chemistry. 267(17): 11888-11897.

18 Driancourt M.A. 2001. Regulation of ovarian follicular dynamics in farm animals. Implications and for manipulation of reproduction. Theriogenology. 55(29): 1211-1239.

19 Duleba A.J., Spaczynski R.Z., Arici A., Carbone R. \& Behrman H.R. 1999. Proliferation and differentiation of rat thecainterstitial cells: comparison of effects induced by platelet-derived growth factor and insulin-like growth factor-I. Biology of Reproduction. 60(3): 546-550.

20 Eriksson A., Siegbahn A., Westermark B., Heldin C.H. \& Claesson-Welsh L. 1992. PDGF a- and b-receptors activate unique and common signal transduction pathways. EMBO Journal. 11(2): 543-550.

21 Fortune J.E. 2003. The early stages of follicular development, p. activation of primordial follicles and growth of preantral follicles. Animal Reproduction Science. 78(3): 135-163.

22 Fortune J.E., Rivera G.M. \& Yang M.Y. 2004. Follicular development: the role of the follicular microenvironment in selection of the dominant follicle. Animal Reproduction Science. 82(1): 109-126.

23 Fredriksson L., Li H. \& Eriksson U. 2004. The Pdgf family: four gene products form five dimeric isoforms. Cytokine Growth Factor Review. 15(4): 197-204. 
24 Frisch S.M. \& Ruoslahti E. 1997. Integrins and anoikis. Current Opinion in Cell Biology. 9(6): 701-706.

25 Fruttiger M., Calver A.R. \& Richardson W.D. 2000. Platelet-derived growth factor is constitutively secreted from neuronal cell bodies but not from axons. Current Biology. 10(20): 1283-1286.

26 Fruttiger M., Karlsson L., Hall A.C., Abramsson A., Calver A.R., Boström H., Willetts K., Bertold C.H., Heath J.K., Betsholtz C. \& Richardson W.D. 1999. Defective oligodendrocyte development and severe hypomyelination in PDGFA knockout mice. Development. 126(3): 457-467.

27 Gaultier C.J. \& Michel J.B. 1999. Angiogenic growth factors. In: Levy B.I. \& Tedgui A. (Eds). Biology of the arterial wall. Massachusetts: Kluwer Academic Publishers, pp.101-113.

28 Gelderloos J.A., Rosenkranz S., Bazenet C. \& Kazlauskas A. 1998. A role for Src in signal relay by the platelet-derived growth factor alpha receptor. Journal of Biological Chemistry. 273(10): 5908-5915.

29 Gnessi L., Basciani S., Mariani S., Arizzi M., Spera G., Wang C., Bondjers C., Karlsson L. \& Betsholtz C. 2000. Leydig cell loss and spermatogenic arrest in platelet-derived growth factor (PDGF)-A-deficient mice. Journal of Biological Chemistry. 149(5): 1019-1025.

30 Gougeon A. 1996. Regulation of ovarian follicular development in primates-facts and hypothesis. Endocrinology Review. 17(2): 121-155.

31 Hammacher A., Hellman U., Johnsson A., Östman A., Gunnarsson K., Westermark B., Wasteson A. \& Heldin C.H. 1988. A major part of platelet-derived growth factor purified from human platelets is a heterodimer of one A and one B chain. Journal of Biological Chemistry. 263(1): 16493-16498.

32 Hammacher A., Niste' R.M., Westermark B. \& Heldin C.H. 1988. A human glioma cell line secretes three structurally and functionally different dimeric forms of platelet-derived growth factor. European Journal of Biochemistry. 176(1): 179186.

33 Harper K.M. \& Brackett B.G. 1993. Bovine blastocyst development after follicle-stimulating hormone and plateletderived growth factor treatment for oocyte maturation in vitro. Zygote. 1(1): 27-34.

34 Hart C.E., Bailey M., Curtis D.A., Osborn S., Raines E., Ross R. \& Forstrom J.W. 1990. Purification of PDGF-AB and PDGFBB from human platelet extracts and identification of all three PDGF dimers in human platelets. Biochemistry. 29(1): 166-172.

35 Hart I.K., Richardson W.D., Heldin C.H., Westermark B. \& Raff M.C. 1989. PDGF receptors on cells of the oligodendrocytetype-2 astrocyte (O-2A) cell lineage. Development. 105(3): 595-603.

36 Heldin C.H., Östman A., Eriksson A., Siegbahn A., Claesson-Welsh L. \& Westermark B. 1992. Platelet-derived growth factor: Isoform-specific signalling via heterodimeric or homodimeric receptor complexes. Kidney International. 41(3): 571-574.

37 Heldin C.H., Östman A. \& Ronnstrand L. 1998. Signal transduction via platelet derived growth factor receptors. Biochimica et Biophysica Acta. 1378(1): 79-113.

38 Heldin C.H., \& Westermark B. 1996. Role of Platelet-Derived Growth Factor In Vivo. In: Clark R.A.F. (Ed). 2nd edn. New York: Plenum, pp.249-273.

39 Heldin C.H. \& Westermark B. 1999. Mechanism of action and in vivo role of platelet-derived growth factor. Physiological Reviews. 79(4): 1283-1316.

40 Heldin P., Pertoft H., Nordlinder H., Heldin C.H. \& Laurent T.C. 1991. Differential expression of platelet-derived growth factor a- and b-receptors on fat-storing cells and endothelial cells of rat liver. Experimental Cell Research. 193(2): 364-369.

41 Hooshmand-Rad R., Yokote K., Heldin C.H. \& Claesson-Welsh L. 1998. PDGF alpha-receptor mediated cellular responses are not dependent on Src family kinases in endothelial cells. Journal of Cell Science. 111(5): 607614.

42 Hoppe J., Weich H.A., Eichner W. \& Tatje D. 1990. Preparation of biologically active platelet-derived growth factor isoforms AA and AB. Preferential formation of AB heterodimers. European Journal of Biochemistry. 187(1): 207-214.

43 Hossain M.Z., Ao P. \& Boynton, A.L. 1998. Rapid disruption of gap junctional communication and phosphorylation of connexin 43 by platelet-derived growth factor in T51B rat liver epithelial cells expressing platelet-derived growth factor receptor. Journal of Cell Physiology. 174(1): 66-77.

44 Hughes A.D., Clunn G.F., Refson J. \& Demoliou-Mason C. 1996. Platelet-derived growth factor (PDGF): actions and mechanisms in vascular smooth muscle. General Pharmacology. 27(7): 1079-1089.

45 Hutt K.J., Mclaughlin E.A. \& Holland M.K. 2006. KIT/KIT Ligand in Mammalian Oogenesis and Folliculogenesis: Roles in Rabbit and Murine Ovarian Follicle Activation and Oocyte Growth. Biology of Reproduction. 75(3): 421-433. 
Brito I.R., Lima I.M.T., Saraiva M.V.A., Silva J.R.V., Rodrigues A.P.R.\& Figueiredo J.R. 2010. Caracterização estrutural e papel do fator de crescimento derivado de plaquetas (PDGF)... Acta Scientiae Veterinariae. 38(3): 221-236.

46 Johnsson A., Heldin C.H., Wasteson A., Westermark B., Deuel T.F., Huang J.S., Seeburg P.H., Gray A., Ullrich A., Scrace G., Stroobant P. \& Waterfield M.D. 1984. The c-sis gene encodes a precursor of the B chain of platelet-derived growth factor. EMBO Journal. 3(5): 921-928.

47 Joly M., Kazlauskas A., Fay F.S. \& Corvera S. 1994. Disruption of PDGF receptor trafficking by mutation of its PI-3 kinase binding sites. Science. 263(5147): 684-687.

48 Jungtäubl H., Peus D., Wlaschek M., Kirchberg K., Meyer-Ingold W., Plewing G. \& Scharfletter-Kochanek K. 1994. The integrated response of human dermal fibroblasts to different cytokine combinations. Archives Dermatological Research. 286(1): 262-163.

49 Junqueira de Azevedo I.L., Farsky S.H., Oliveira M.L. \& Ho P.L. 2001. Molecular cloning and expression of a functional snake venom vascular endothelium growth factor (VEGF) from the Bothrops insularis pit viper. A new member of the VEGF family of proteins. Journal of Biological Chemistry. 276(43): 39836-39842.

50 Kamat A. \& Carpenter G. 1997. Phospholipase C-gl: regulation of enzyme function and role in growth factor-dependent signal transduction. Cytokine Growth Factor Review. 8(2): 109-117.

51 Karlsson L., Bondjers C. \& Betsholtz C. 1999. Roles for PDGF-A and sonic hedgehog in development of mesenchymal components of the hair follicle. Development. 126(12): 2611-2621.

52 Karlsson L., Lindahl P., Heath J.K. \& Betsholtz C. 2000. Abnormal gastrointestinal development in PDGF-A and PDGFR$\alpha$ ?deficient mice implicates a novel mesenchymal structure with putative instructive properties in villus morphogenesis. Development. 127(16): 3457-3466.

53 Kelly J.D., Haldeman B.A., Grant F.J., Murray M.J., Seifert R.A., Bowen-Pope D.F., Cooper J.A. \& Kazlauskas A. 1991. Platelet-derived growth factor (PDGF) stimulates PDGF receptor subunit dimerization and intersubunit transphosphorylation. Journal of Biological Chemistry. 266(14): 8987-8992.

54 Kidder G.M. \& Mhawi A.A. 2002. Gap junctions and ovarian folliculogenesis. Reproduction. 123(5): 613.

55 Knecht M. \& Catt K.J. 1983. Modulation of cAMP mediated differentiation in ovarian granulosa cells by epidermal growth factor and platelet-derived growth factor. Biological Chemistry. 258(5): 2789-2794.

56 Kohler N. \& Lipton A. 1974. Platelets as a source of fibroblast growth-promoting activity. Experimental Cell. Research. 87(2): 297-301.

57 Koyama H., Nishizawa Y., Hosoi M., Fukumoto S., Kogawa K., Shioi A. \& Morii H. 1996. The fumagillin analogue TNP- 470 inhibits DNA synthesis of vascular smooth muscle cells stimulated by platelet-derived growth factor and insulin-like growth factor-I: possible involvement of cyclin-dependent kinase 2. Circulation Research. 79(4): 757-764.

58 Kypta R.M., Goldberg Y., Ulug E.T. \& Courtneidge S.A. 1990. Association between the PDGF receptor and members of the src family of tyrosine kinases. Cell. 62(3): 481-492.

59 LaRochelle W.J., May-Siroff M., Robbins K.C. \& Aaronson S.A. 1991. A novel mechanism regulating growth factor association with the cell surface: identification of a PDGF retention domain. Genes \& Development. 5(7): 1191-1199.

60 Lee V.H. 2000. Expression of Rabbit Zona Pellucida-1 Messenger Ribonucleic Acid During Early Follicular Development. Biology of Reproduction. 63(2): 401-408.

61 Lei H. \& Kazlauskas A. 2008. Focus on Molecules: Platelet-derived growth factor C, PDGF-C. Experimental Eye Research . 86(5): 711-712.

62 Levéen P., Pekny M., Gebre-Medhin S., Swolin B., Larsson E. \& Betsholtz C. 1994. Mice deficient for PDGF B show renal, cardiovascular, and hematological abnormalities. Genes \& Developement. 8(16): 1875-1887.

63 Li X. \& Eriksson U. 2003. Novel PDGF family members: PDGF-C and PDGF-D. Cytokine \& Growth Factor Reviews. 14(2): 91-98.

64 Li X., Pontén A., Aase K., Karlsson L., Abramsson A., Uutela M., Bäckström G., Hellström M., Boström H., Li H., Soriano P., Betsholtz C., Heldin C.H., Alitalo K., Östman A. \& Eriksson U. 2000. PDGF-C is a new protease-activated ligand for the PDGF $\alpha$-receptor. Nature Cell Biology. 2(5): 302-309.

65 Lopata A. \& Oliva K. 1993. Chorionic gonadotrophin secretion by human blastocysts. Human Reproduction. 8(6): $932-938$.

66 Lowenstein E., Mohammadi M., Margolis B. \& Schlessinger J. 1993. The function of GRB2 in linking the insulin receptor to Ras signaling pathway. Science. 260(5116): 1953-1955.

67 Matoskova B., Rorsman F., Svensson V. \& Betsholtz C. 1989. Alternative splicing of the platelet-derived growth factor Achain transcript occurs in normal as well as tumor cells and is conserved among mammalian species. Molecular and Cellular Biology. 9(7): 3148. 
68 May J.V., Bridge A.J., Gotcher E.D. \& Gangrade B.K. 1992. The regulation of porcine theca cell proliferation in vitro: synergistic actions of epidermal growth factor and platelet-derived growth factor. Endocrinology. 131(2): 689-697.

69 May J.V., Frost J.P. \& Bridge A.J. 1990. Regulation of Granulosa Cell Proliferation: Facilitative Roles of Platelet-Derived Growth Factor and Low Density Lipoprotein. Endocrinology. 126(6): 2896-2905.

70 McDonald J.A., Pinheiro E.M. \& Montell D.J. 2003. PVF1, a PDGF/VEGF homolog, is sufficient to guide border cells and interacts genetically with Taiman. Development. 130(20): 3469-3478.

71 McWilliam R., Leake R.E. \& Coutts J.R. 1995. Growth factors in human ovarian follicle fluid and growth factor receptors in granulosa-luteal cells. International Journal of Biological Markers. 10(4): 216-20.

72 Meyer-Ingold W. \& Eichner W. 1995. Platelet-Derived Growth Factor. Cell Biology International. 19(5): $389-398$.

73 Michel U., Liidemann S., Jarry H. \& Wuttke W. 1991. Effects of Growth Factors and Hormones on Basal and FSH-stimulated Inhibin Production by Porcine Granulosa Cells In vitro. Reproduction, Fertility and Development. 3(2): $201-213$.

74 Mondschein J.S. \& Schomberg D.W. 1981. Platelet-derived growth factor enhances granulosa cell luteinizing hormone receptor induction by follicle-stimulating hormone and serum. Endocrinology. 109(1): 325-327.

75 Mondschein J.S. \& Schomberg D.W. 1984. Effects of partially and more highly purified platelet-derived growth factor preparations on luteinising hormone receptor induction in granulosa cell cultures. Biology of Reproduction. 30(3): 603-608.

76 Mori S., RöNnstrand L., Claesson-Welsh L. \& Heldin C.H. 1994. A tyrosine residue in the juxtamembrane segment of the platelet-derived growth factor b-receptor is critical for ligand-mediated endocytosis. Journal of Biological Chemistry. 269(7): 4917-4921.

77 Nascimento A.A., Pinheiro N.L., Sales A. \& Viana J.H.M. 2003. Correlação morfométrica do ovário de fêmeas bovinas em diferentes estádios reprodutivos. Brazilian Journal of Veterinary Research and Animal Science. 40(2): 126-132.

78 Nilsson E.E., Detzel C. \& Skinner M.K. 2006. Platelet-derived growth factor modulates the primordial to primary follicle transition. Reproduction. 131(6): 1007-1015.

79 Nister M., Hammacher A., Mellstrom K., Sieobahn A., Ronnstrand L., Westermark B. \& Heldin C.H. 1988. A gliomaderived PDGF A chain homodimer has different functional activities than a PDGF AB heterodimer purified from human platelets. Cell. 52(6): 791-799.

80 Okamura Y., Myoumoto A., Manabe N., Tanaka N., Okamura H. \& Fukumoto M. 2001. Protein tyrosine kinase expression in the porcine ovary. Molecular Human Reproduction. 7(8): 723-729.

81 Omura T., Heldin C.H. \& Östman A. 1997. Immunoglobulin-like Domain 4-mediated Receptor-Receptor Interactions Contribute to Platelet-derived Growth Factor-induced Receptor Dimerization. Journal of Biological Chemistry. 272(19): 12676-12682.

82 Östman A., Andersson M., Betsholtz C., Westermark B. \& Heldin C.H. 1991. Identification of a cell retention signal in the B-chain of platelet-derived growth factor and in the long splice version of the A-chain. Cell Regulatation. 2(7): 503-512.

83 Östman A., Thyberg J., Westermark B. \& Heldin C.H. 1992. PDGF-AA and PDGF-BB biosynthesis: proprotein processing in the Golgi complex and lysosomal degradation of PDGF-BB retained intracellularly. Journal of Cell Biology. 118(3): 509-519.

84 Parrott J.A. \& Skinner M.K. 1999. Kit-ligand/stem cell factor induces primordial follicle development and initiates folliculogenesis. Endocrinology. 140(9): 4262-4271.

85 Parrott J.A. \& Skinner M.K. 2000. Kit ligand actions on ovarian stromal cells: effects on theca cell recruitment and steroid production. Molecular Reproduction and Development. 55(1): 55-64.

86 Pfeilschifter J., Krempien R., Naumann A., Gronwald R.G., Hoppe J. \& Ziegler R. 1992. Differential effects of plateletderived growth factor isoforms on plasminogen activator activity in fetal rat osteoblasts due to isoform- specific receptor functions. Endocrinology. 130(4): 2059-2066.

87 Pietrowski D. \& Keck C. 2004. Differential regulation of ANG2 and VEGF-A in human granulosa lutein cells by choriogonadotropin. Experimental and Clinical Endocrinology \& Diabetes. 112(4): 208-214.

88 Pineda M.H. 1989. Female reproductive system. In: McDonald L.E. (Ed). Veterinary Endocrionology and Reproduction. Philadelphia: Lea \& Febiger, pp.303-354.

89 Pinkas H., Fisch B., Rozansky G., Felz C., Kessler-Icekson G., Krissi H., Nitke S., AoA. \& Abir R. 2008. Platelet-derived growth factors (PDGF-A and -B) and their receptors in human fetal and adult ovaries. Molecular Human Reproduction. 14(4): 199-206.

90 Raines E.W., Bowen-Pope D.F. \& Ross R. 1990. Platelet-Derived Growth Factor. In: Sporn M.B. \& Roberts A.B. (Eds). Handbook of experimental pharmacology. Peptide growth factors and their receptors. Heidelberg: Springer-Verlag, pp.173-262. 
91 Rappolee D.A., Breener C.A., Schultz R., Mark D. \& Werb Z. 1988. Developmental expression of PDGF, TGF-a, and TGFB genes in preimplantation mouse embryos. Science. 241(4874): 1823-1825.

92 Reigstad L.J., Varhaug J.E. \& Lillehaug J.R. 2005. Strutuctural and functional specificities of PDGF-C and PDGF-D, the novel members of the platelet-derived growth factors family. FEBS Journal. 272(22): 5723-5741.

93 Robbins K.C., Leal F., Pierce J.H. \& Aaronson S.A. 1985. The v-sis/PDGF-2 transforming gene product localizes to cell membranes but is not a secretory protein. EMBO Journal. 4(7): 1783-1792.

94 Rorsman F., Leveen P. \& Betsholtz C. 1992. Characterization of the mouse PDGF A-chain gene. Evolutionary conservation of gene structure, Nucleotide Sequence and Alternative Splicing. Growth Factors. 6(4): 303-313.

95 Ross R., Glomsett J., Kariya B. \& Harker L.A. 1974. Platelet-Dependent Serum Factor That Stimulates The Proliferation Of Arterial Muscle Cells In Vitro. Proceedings of the National Academy of Sciences USA. 71(4): 1207-1210.

96 Ross R., Raines E. \& Bowen-Pope D. 1982. Growth factors from platelets, monocytes, and endothelium: their role in cell proliferation. Annals of the New York Academy of Sciences. 397(1): 18-24.

97 Rubin K., Tingstro A.M., Hansson G.K., Larsson E., RoNnstrand L., Klareskog L., Claesson-Welsh L., Heldin C.H., Fellstro B.M. \& Terracio L. 1988. Induction of B-type receptors for platelet-derived growth factor in vascular inflammation: possible implications for development of vascular proliferative lesions. Lancet. 1(8599): 1353-1356.

98 Schmahl J., Rizzolo K. \& Soriano P. 2008. The PDGF signaling pathway controls multiple steroid-producing lineages. Genes \& Development. 22(23): 3255-3267.

99 Shores E.M. \& Hunter M.G. 2000. The influence of blood cells and PDGF on porcine theca cell function in vitro. Animal Reproduction Science. 64(3-4): 247-258.

100 Siegbahn A., Hammacher A., Westermark B. \& Heldin C.H. 1990. Differential effects of the various isoforms of platelet derived growth factor on chemotaxis of fibroblasts, monocytes, and granulocytes. Journal of Clinical Investigation. 85(3): 916-920.

101 Siegfried G., Khatib A.M., Benjannet S., Chretien M. \& Seidah N.G. 2003. The proteolytic processing of pro-plateletderived growth factor-A at RRKR(86) by members of the proprotein convertase family is functionally correlated to platelet-derived growth factor-A-induced functions and tumorigenicity. Cancer Research. 63(7): 1458-1463.

102 Silva J.R.V. 2005. Growth factors in goat ovaries and the role of activina-A in the development of early-staged follicles. 142p. Utrecht, Holland. PhD Thesis. Faculty of Veterinary Medicine, Utrecht University.

103 Skinner M.K. 2005. Regulation of primordial follicle assembly and development. Human Reproduction Update. 11(5): 461-471.

104 Skolnik E.Y., Batzer A., Li N., Lee C.H., Lowestein E., Mohammadi M., Margolis B. \& Schlessinger J. 1993. The function of GRB2 in linking the insulin receptor to Ras signaling pathways. Science. 260(5116): 1953-1955.

105 Sleer L.S. \& Taylor C.C. 2007. Cell-type localization of platelet-derived growth factors and receptors in the postnatal rat ovary and follicle. Biology of Reproducion. 76(3): 379-390.

106 Sleer L.S. \& Taylor C.C. 2007. Platelet-Derived Growth Factors and Receptors in the Rat Corpus Luteum: Localization and Identification of an Effect on Luteogenesis. Biology of Reproduction. 76(3): 391-400.

107 Smits A., Hermanson M., Niste M.R., Karnushina I., Heldin C.H., Westermark B. \& Funa K. 1989. Rat brain capillary endothelial cells express functional PDGF B-type receptors. Growth Factors. 2(1): 1-8.

108 Soriano P. 1994. Abnormal kidney development and hematological disorders in PDGF b-receptor mutant mice. Genes \& Development. 8(16): 1888-1896.

109 Soriano P. 1997. The PDGF alpha $\alpha$ receptor is required for neural crest cell development and for normal patterning of the somites. Development. 124(14): 2691-2700.

110 Sorkin A., Westermark B., Heldin C.H. \& Claessonwelsh L. 1991. Effect of receptor kinase inactivation on the rate of internalization and degradation of PDGF and the PDGF b-receptor. Journal of Cell Biology. 112(3): 469-478.

111 Stroobant P. \& Waterfield M.D. 1984. Purification and properties of porcine platelet-derived growth factor. EMBO Journal. 3(12): 2963-2967.

112Swan D.C., McBride O.W., Robbins K.C., Keithley D.A., Reddy E.P. \& Aaronson S.A. 1982. Chromosomal mapping of the simian sarcoma virus oncogene analogue in human cells. Proceedings of the National Academy of Sciences USA. 79(15): 4691-4695.

113 Taylor C.C. 2000. Platelet-derived growth factor activates porcine thecal cellphosphatidylinositol-3-kinase-Akt/PKB and ras-extracellular signal-regulated kinase-1/2 kinase signaling pathways via the platelet-derived growth factor-beta receptor. Endocrinology. 141(4): 1545-1553. 
Brito I.R., Lima I.M.T., Saraiva M.V.A., Silva J.R.V., Rodrigues A.P.R. \& Figueiredo J.R. 2010. Caracterização estrutural e papel do fator de crescimento derivado de plaquetas (PDGF)... Acta Scientiae Veterinariae. 38(3): 221-236.

114 Twamley-Stein G.M., Pepperkok R., Ansorge W. \& Courtneidge S.A. 1993. The Src family tyrosine kinases are required for platelet-derived growth factor-mediated signal transduction in NIH 3T3 cells. Proceedings of the National Academy of Sciences USA. 90(16): 7696-7700.

115 Uutela M., Lauren J., Bergsten E., Li X., Horelli-Kuitunen N., Eriksson U. \& Alitalo K. 2001. Chromosomal location, exon structure, and vascular expression patterns of the human PDGFC genes. Circulation. 103(18): 2242-2247.

116 Valgeirsdóttir S., Paukku K., Silvennoinen O., Heldin C.H. \& Claesson-Welsh L. 1998. Activation of Stat5 by plateletderived growth factor (PDGF) is dependent on phosphorylation sites in PDGF b-receptor juxtamembrane and kinase insert domains. Oncogene. 16(4): 505-515.

117 Van Den Hurk R. \& Zhao J. 2005. Formation of mammalian oocytes and their growth, differentiation and maturation within ovarian follicles. Theriogenology. 63(6): 1717-1751.

118 Vanhaesebroeck B., Leevers S.J., Panayotou G. \& Waterfield M.D. 1997. Phosphoinositide 3-kinases: a conserved family of signal transducers. Trends in Biochemical Science. 22(7): 267-272.

119 Vassbotn F.S., Havnen O. K., Heldin C.H. \& Holmsen H. 1994. Negative feedback regulation of human platelets via autocrine activation of the platelet-derived growth factor a-receptor. Journal of Biological Chemistry. 269(19): 13874-13879.

120 Webb R., Nicholas B., Gong J.G., Campbell B.K., Gutierrez C.G., Garverick H.A. \& Armstrong D.G. 2003. Mechanisms regulating follicular development and selection of the dominant follicle. Reproduction Supplement. 61(1): 71-90.

121 Witte L.D., Kaplan K.L., Nossel H.L., Lages B.A., Weiss H.J. \& Goodman D.S. 1978. Studies of the release from human platelets of the growth factor for cultured human arterial smooth muscle cells. Circularion Research. 42(3): $402-409$.

122 Wu Y.T., Tang L., Cai J., Lu X.E., Xu J., Zhu X.M., Luo Q. \& Huang H.F. 2007. High bone morphogenetic protein-15 level in follicular fluid is associated with high quality oocyte and subsequent embryonic development. Human Reproduction. 22(6):1526-1531.

123 Yamazaki Y., Takani K., Atoda H. \& Morita T. 2003. Snake venom vascular endothelial growth factors (VEGFs) exhibit potent activity through their specific recognition of KDR (VEGF receptor 2). Journal of Biological Chemistry. 278(52): 51985-51988.

124 Yao R. \& Cooper G.M. 1995. Requirement for phosphatidylinositol-3 kinase in the prevention of apoptosis by nerve growth factor. Science. 267(5206): 2003-2006.

125 Yokote K., Mori S., Siegbahn A., RöNnstrand L., Wernstedt C., Heldin C.H. \& Claesson-Welsh L. 1996. Structural determinants in the platelet-derived growth factor a-receptor implicated in modulation of chemotaxis. Journal of Biological Chemistry. 271(9): 5101-5111.

126 Yoon S.J., Kim K.H., Chung H.M., Choi D.H., Lee W.S., Cha K.Y. \& Lee K.A. 2006. Gene expression profiling of early follicular development in primordial, primary, and secondary follicles. Fertility and Sterility. 85(1): 193-203.

127 Young R.M, Mendonza A.E., Collins T. \& Orkin S.H. 1990. Alternatively spliced platelet-derived growth factor A-chain transcripts are not tumor specific but encode normal cellular proteins. Molecular and Cellular Biology. 10(11): 6051-6054.

128 Yu J.C., Heidaran M.A., Pierce J.H., Gutkind J.S., Lombardi D., Ruggiero M. \& Aaronson S.A. 1991. Tyrosine mutations within the a platelet-derived growth factor receptor kinase insert domain abrogate receptor-associated phosphatidylinositol-3 kinase activity without affecting mitogenic or chemotactic signal transduction. Molecular and Cellular Biology. 11(7): 3780-3785.

129Yu, J.C., Mahadevan D., LaRochelle W.J., Pierce J.H. \& Heidaran M.A. 1994. Structural coincidence of a-PDGFR epitopes binding to platelet-derived growth factor-AA and a potent neutralizing monoclonal antibody. Journal of Biological Chemistry. 269(14): 10668-10674.

130 Zwerner J.P. \& May W.A. 2001. PDGF-C is an EWS/FLI induced transforming growth factor in Ewing family tumors. Oncogene. 20(5): 626-633. 
